\title{
IMPLICIT EGOTISM IN JAPAN: PREFERENCE FOR FIRST AND FAMILY NAME INITIALS*
}

\author{
Megumi Komori** AND KoJi Murata $^{* * *}$
}

\begin{abstract}
A recent study suggested that the name letter effect is a product of unconscious selfregulation, which people under threat use to enhance their self-esteem. This study demonstrated the name letter effect in Japanese participants using the English alphabet, and examined if preference for their name letter changes in response to threat. We manipulated the strength of self-threat by assigning the participants to a difficult or easy quiz. As a result, we successfully demonstrated the name letter effect. The strength of the first and family name letter preferences differed according to the participants' gender. Implicit egotism is partially observed among male participants, thus they boosted their name letter preference after being exposed to a selfthreatening task.
\end{abstract}

\section{Introduction}

Positive evaluation towards the self influences our judgment and behaviors. It motivates us to challenge the difficult situation, enables our subjective happiness and prevents physical or mental illness, such as depression (Taylor, 1989). As is this case for attitude, researchers suggest that we have explicit and implicit self-esteem (e.g., Greenwald \& Banaji, 1995) . Whereas explicit self-esteem is sometimes skewed by external forces such as social desirability, implicit self-esteem is thought to reflect immediate, automatic mental processes which concern the self directly. There are many techniques to measure people's implicit self-esteem (e.g., Implicit Association Test, subliminal priming task, word completion task; cf. Bosson, Swann \& Pennebaker, 2000). One technique with which to measure implicit self-esteem is the name letter effect (Koole \& Pelham, 2003).

* This study was presented at the 4th Annual Convention of Society for Personality and Social Psychology in Los Angels, USA, 2003. This study was partly supported by a Grant-in-Aid for Scientific Research (No.19330141) from the Japan Society for the Promotion of Science to Koji Murata. We are grateful to Yoshihisa Naka and Kimihisa Watanabe for their help in conducting this research. Correspondence concerning this article should be addressed to Megumi Komori or Koji Murata, Graduate School of Social Sciences, Hitotsubashi University, 2-1, Naka, Kunitachi, Tokyo, Japan; email; sd051007@g.hit-u.ac.jp or cs00046@srv.cc.hit-u.ac.jp

** Doctoral student at the Graduate School of Social Sciences, Hitotsubashi University

*** Professor of Social Psychology, Hitotsubashi University 


\section{Name Letter Effect}

Research on the name letter effect demonstrates that people prefer the letters in their own names to letters that are not in their names (Nuttin, 1985). People also show preference for the number of their birth month and birthday, which is referred to as the birth number effect.

Name letter effect is reported throughout many countries such as Europe (Nuttin, 1987), the Netherlands (Koole, Dijksterhuis, \& van Knippenberg, 2001), the United States (Johnson, 1986, reported in Greenwald \& Banaji, 1995), Canada (Hodson \& Olson, 2005), and Japan (Kitayama \& Karasawa, 1997).

In Japan, Kitayama and Karasawa (1997) demonstrated the name letter effect using Japanese alphabet (hiragana) and the birthday number effect in Japanese participants. In their study, participants rated the letters in the Japanese alphabet one by one and then indicated the letters in their name. The results from the study showed that participants preferred the letters in their name to the other letters, i.e., the letters were preferred if they were included in their initials than when they were not. They also found a gender difference in name letter effect, such that male participants evaluated the initials in their family name more favorably, whereas female participants preferred their first name initials. This tendency was described as a reflection of the marital system in Japan, where the wife changes her surname to the husband's surname when they are married.

Name letter effect is said to indicate the implicit side of self-esteem and to be independent from mere exposure effects because the preference effect was stronger within people with rare names than those with common names (Jones, Pelham, \& Mirenberg, 2002). The name letter effect has demonstrated proven stability over a 4 week period (Koole, et al., 2001).

\section{Implicit Egotism}

Previous research showed that we use implicit self-esteem strategically for the purpose of coping with a situation where the self is threatened. Jones and colleagues (2002) manipulated the threat to participants' self concept through a task in which they wrote about themselves in a self-critical way (high threat condition) or a self-affirmative way (low threat condition), and measured their preference for English letters. The results showed that in the high threat condition, participants with high explicit self-esteem rated their own name letters more favorably than did participants with low self-esteem. Based on these results, they argued that implicit self-esteem functions to keep one's self-regard in the face of threat and that this regulation can be demonstrated through name letter effect. They defined this "unconscious tendency to prefer things that resemble the self" (Pelham, Carvallo, \& Jones, 2005, p.106) as implicit egotism.

Previous research has shown that implicit egotism directs our lifetime decisions (e.g., where to live, what to do for a living). Pelham, Mirenberg and Jones (2002) conducted archival research and showed that there is a statistically significant tendency for individuals to live in a state whose name resembles their own (e.g., Florence tends to live in Florida). This surprising result remained significant after they ruled out confounding variables, such as the possibility that the habitants were named after their states. They also found the same relationship in eight of the largest U.S. or Canadian cities and surnames. 


\section{Purpose of This Research}

In this paper, we attempted to replicate the name letter effect in Japan, using initials from the English alphabet. Though the mother tongue in Japan is not English, the Japanese have the opportunity to write their names, especially their initials using English letters. It is predicted that participants will prefer the letters in their initials to those which their initials do not contain. Kitayama and Karasawa (1997) demonstrated the name letter effect among Japanese participants. They also found a gender difference in the strength of the name letter effect, showing that male participants preferred the letters in their family name, while female participants preferred the letters in their first name. We also attempted to replicate this pattern among a different population of Japanese participants using English letters.

Previous research argued that the name letter effect is an example of implicit egotism and is conceptualized as the product of unconscious self-regulation processes (Jones, et al., 2002). In the face of ego-threat, we are likely to increase preference for things which resemble or relate to the self, for the purpose of maintaining our self-esteem. We concur with these findings, therefore the second goal of our study is to replicate the effect of threat on automatic self-enhancing.

Jones et al., (2002) showed an interaction between self-threat and explicit self-esteem and found that implicit egotism was present only when the participants' explicit self-esteem was high. People with explicit low self-esteem showed a reversed pattern, thus they decreased their preference for the letters in their name in the face of threat. Some researchers insist that the Japanese have low self-esteem on average, as compared with people in Western (Europe or United States) countries (Heine, Lehman, Markus, \& Kitayama, 1999). However, with Japanese participants, there were mixed findings on explicit self-esteem differences in how people respond to threat, especially when we utilized indirect or implicit strategies (Ito, 1998) . Therefore, we predicted that there is implicit egotism among the Japanese regardless of high or low trait self-esteem.

Alternatively, previous research had only measured trait self-esteem in order to study the relationship between implicit and explicit self-esteem. For the explicit level, self-esteem is damaged when the self is threatened. We measured participants' state self-esteem and trait selfesteem separately, and examined the relationship between implicit and explicit self-esteem in greater detail.

In this study, participants solved a series of math problems before rating their preference of letters. Half of them engaged in a difficult quiz in order to expose their self-regard to threat. The remaining half of the participants solved a relatively easy quiz which was intended to induce little or no threat. We also intended to manipulate threatening conditions through difficult or easy math problems. It was hypothesized that the name letter effect would emerge, thus people would prefer the letters in their initials to the other letters, or like them better than other people without those letters in their initials. Moreover, it was also hypothesized that people in the high-threat condition would engage in an implicit self-regulation process, and would like the letters in their initials better than those in the control condition. 


\section{Method}

\section{Participants}

Participants were 69 undergraduate students (40 males and 29 females) in an introductory social psychology course at Hitotsubashi University (Tokyo, Japan). Participants received course credit for attending the class on the day of the study. They were randomly assigned to a threat or control condition.

\section{Procedures}

At the last quarter of a regular class session, participants received a packet of experimental materials and completed them at their own pace. The study was described as a survey designed to assess the relationship between need for uniqueness and problem-solving ability.

Threat manipulation. After completing a 10-item uniqueness scale (a filler task), participants in the threat condition were asked to solve 8 highly difficult mathematical problems in 5 minutes. Participants assigned to the control condition were asked to solve 8 relatively easy math problems in 5 minutes. Participants in both conditions were required to complete the math in their heads, and only write the answers on the paper. We did not keep scores and the participants did not receive feedback on the math problems.

Manipulation check. Immediately following the manipulation, participants completed a state self-esteem scale (Heatherton \& Polivy, 1991; 16-items) on a 5-point scale ranging from 1 (not at all) to 5 (very likely). We also asked the participants how they felt about their performance on the math quiz on a 5-point scale ranging from 1 (not poor) to 5 (very well).

Name-letter initial preferences. All the participants were asked to rehearse a 6-digit number while they responded to the next questions. We included this working memory task to ensure the implicit nature of the following preference measure. On the next page, they rated their preferences for 20 letters of the English alphabet which were used in Japanese name initials ( $\mathrm{L}, \mathrm{P}, \mathrm{Q}, \mathrm{V}, \mathrm{X}$, and $\mathrm{Z}$ were excluded). Those 20 letters were presented in a random order and were rated on a 7-point scale ranging from 1 (do not like at all) to 7 (like it very much). We reminded participants to keep the 6-digit number in mind while rating the letters.

Trait self-esteem and demographic variables. Immediately following the preference measure, we asked the participants to report the rehearsed number. Sixty-three of 65 participants reported the correct number. Next, the participants completed the Rosenberg's Trait Self-Esteem Scale (Rosenberg, 1965) on a 5-point scale ranging from 1 (not at all) to 5 (very likely). Finally, the participants were asked to write their demographic information such as, blood-type, gender, family and first name initials, age, if they had seen the same math problems before and if they were an international student. Participants who had completed the survey were allowed to leave the class. When they left the room, participants received a sheet that included an explanation with debriefing about the study. 


\section{Results}

The results from 4 international students were discarded from the analysis because they could be assumed to use a different letter system for most of their lives. As a result, the data from 65 participants ( 37 males, 28 females) was analyzed. Thirty participants had been assigned to the threat condition and 35 were assigned to the control condition.

Manipulation checks. We conducted two types of manipulation checks. First, we examined if there was any difference in the participants' state self-esteem. Participants in the threat condition $(M=48.4)$ had lower state self-esteem than participants in the control condition $(M=52.5)$. A 2 (condition) $\times 2$ (gender) ANOVA for the state self-esteem revealed a nearly significant main effect for the experimental condition $(F(1,59)=3.97, p=.051)$. Secondly, we examined the participants' ratings for their perceived performance score. The participants in the threat condition $(M=1.37)$ perceived their performance score to be worse than the participants in the control condition $(M=3.69$ ). A 2 (condition) $\times 2$ (gender) ANOVA for the perceived performance only revealed a main effect for experimental condition $(F(1,60)$ $=99.7, p<.001)$. The correlation between perceived difficulty and state self-esteem was significant $(\mathrm{r}=.25, p<.05)$.

Considering the results of two types of manipulation checks, the threat manipulation seemed to succeed. However, in the control condition, there were 9 participants who answered "not sure" and 4 participants who answered "poor", so some participants may have perceived the easy quiz as difficult, and their self-view might be damaged to some extent.

Name letter effects. We computed relative evaluations of name letter initials according to the procedures of Kitayama and Karasawa (1997). We first computed a baseline evaluation of each letter for those whose names did not include it. Subsequently, baseline evaluations were aggregated across both conditions for each letter. Next, for each respondent, a difference score was computed between the evaluations of each of the name letters and the corresponding noname evaluations to yield a relative preference score. Over-evaluation of name letters is indicated by positive relative evaluations (Koole et al., 2001).

We examined if the name letter effect emerged and if there was a different pattern between family and first name letter preference according to gender(Table 1). For the male participants, the name letter preference was more pronounced for the family names. For the female participants, the pattern reversed and the name letter preference was more pronounced for the first names. Additionally, on average, participants' relative preferences for family $(M=0.88)$ and first $(M=1.11)$ name initials were positive and significantly different from zero in all conditions $(t \mathrm{~s}>6.0, p \mathrm{~s}<.001)$. First and family name preference scores had a low but significant correlation $(r=.30, p<.02)$.

Thus, our findings confirmed the name letter effect with English initials among Japanese

Table 1. Relative Preference for the Family and First Name

\begin{tabular}{lcccc}
\hline & \multicolumn{2}{c}{ Family name } & \multicolumn{2}{c}{ First name } \\
Gender & $M$ & $S D$ & $M$ & $S D$ \\
\hline Male & 1.15 & 1.25 & 0.90 & 1.35 \\
Female & 0.53 & 1.29 & 1.40 & 1.04 \\
\hline
\end{tabular}


participants. There was no significant correlation between name letter preference and both trait self-esteem total score $(r \mathrm{~s}<.20$, ns.) and state self-esteem total score $(r \mathrm{~s}<.06$, ns.). Therefore, two types of explicit self-esteem (i.e. trait and state) and implicit self-esteem (i.e. name letter effect) could be regarded as independent.

Implicit self-regulation. We investigated whether participants showed implicit egotism, i.e. they boosted the preference for their name letter in the face of ego-threat. We analyzed the family and first name letter preference separately because prior analyses implied a different meaning in family and first name preference according to the participants' gender.

A 2 (condition) $\times 2$ (gender) ANOVA for the family name initial revealed a main effect for gender $(F(1,61)=4.10, p<.05)$, and the name letter effect for the family name was more prominent among male participants $(M=1.15)$ than female participants $(M=0.53)$. The gender difference was larger in the threat condition, but there was neither a main effect for experimental condition nor significant interaction (Figure 1, left side). A $2 \times 2$ ANOVA for the first name initial showed a nearly significant main effect for condition $(F(1,61)=2.52, p<$ .12). Participants' name letter preferences tended to increase after the threat $(M=1.39)$ rather than control $(M=0.87)$ condition as predicted. It also showed a nearly significant main effect for gender $(F(1,61)=2.44, p<.13)$ showing that female participants $(M=1.40)$ tended to prefer their first name letters better than male participants $(M=0.90)$ did. However, there was no significant interaction (Figure 1, right side).

We did not include trait self-esteem in the prior analysis because there was no significant correlation between trait self-esteem and name letter preference. Moreover, when included, explicit trait self-esteem did not moderate these main effects.

So far, the results imply that male participants in the threat condition boosted their name letter preference compared with male participants in the control condition. To examine the observed gender difference more carefully, we combined first and family name letter preferences together, and conducted a between-subjects (condition) t-test only with data from the male participants. Results showed that the name letter preference was significantly stronger $(t(35)=2.04, p<.05)$ among male participants in the threat condition $(M=2.80)$ than among those in the control condition $(M=1.41)$. The same analysis revealed no significant results among female participants.

Fig. 1. Name Letter Preference Score by Condition and Participant Gender

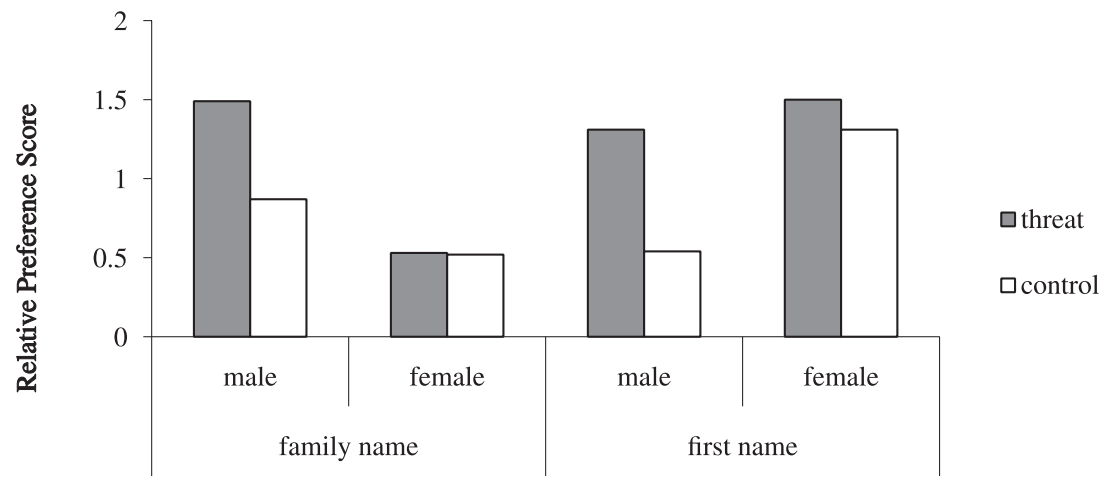


Taken together, the present findings indicate that the automatic self-serving process becomes activated among male Japanese students in the face of ego-threat.

\section{Discussion}

This research explored the implicit side of our self-esteem and its function through name letter effect. The first aim of the study was to replicate the name letter effect among Japanese people using English initials. It was also predicted that male participants would show stronger name letter effect in their family names, whereas female participants would show stronger name letter effect in their first names. The second aim of the research was to examine the possibility of implicit egotism, and to observe if people increase the preference for their name letter when their self-image was threatened.

In our study, participants constantly showed the name letter effect, thus their preference for their name letter was stronger than either other letters or the average preference score(i.e. mean liking of each letter for those whose names did not include it; Kitayama \& Karasawa, 1997). This result suggests that Japanese people have positive feelings toward themselves. The name letter preference was not correlated with other measures of explicit self-esteem, which could be taken as evidence that the name letter effect reflects different aspects of self-view (cf. Wilson \& Dunn, 2004). Furthermore, the relationship between family/first name and gender replicated the results of previous research. This could be interpreted as a reflection of the Japanese marital system, where women are generally expected to take their husband's name after marriage (Kitayama \& Karasawa, 1997). In addition, men often call each other by their family names even though they are close friends, whereas women often call each other by their first names as a nickname. This might explain the different frequency between first and family names, which might influence the difference in positive connection between the self and name letters.

In our data, there was only marginal evidence of implicit egotism among male participants. Male participants who received a self-threatening task tended to boost their preference for the name letters compared with those who received a non-threatening task. On the explicit level, self-esteem is reduced if people are involved in a self-threatening event. However, on the implicit level, they might automatically engage in self-affirmative behavior to protect their positive self-view. However, the results for implicit egotism did not reach a statistically significant level. This might be due to the small number of participants, or because some participants in the control condition could not solve the math problems and might have felt threatened, although they were in the control condition.

Alternatively, female participants did not show any different patterns according to the difficulty of the math problems. Female participants might have stable attitudes toward their name letter initials. In addition, female students generally tend to place a distance between themselves and math, so they might not perceive the math quiz to be self-relevant, thus feel no threat regardless of the difficulty manipulation that we used in this experiment. Female participants might engage in implicit egotism as well if they were faced with a more selfrelated kind of threat.

To summarize, we demonstrated the name letter effect among Japanese participants, and different patterns in first/family name letter preferences emerged according to gender. The evidence for the implicit egotism was only marginally seen among male participants. Therefore, 
it is suggested that implicit side of self-esteem serve as silent force behind our everyday scenes in certain cases.

\section{REFERENCES}

Bosson, J., Swann, W. B., Jr., \& Pennebaker, J. (2000). Stalking the perfect measure of implicit self-esteem: The blind men and the elephant revisited? Journal of Personality and Social Psychology, 79, 631-643.

Greenwald, A. G., \& Banaji, M. R. (1995). Implicit social cognition: Attitudes, self-esteem, and stereotypes. Psychological Review, 102, 4-27.

Heine, S. J., Lehman, D. R., Markus, H. R., \& Kitayama, S. (1999). Is there a universal need for positive self-regard? Psychological Review, 106, 766-794.

Hodson, G., \& Olson, J. M. (2005). Testing the generality of the name letter effect: Name initials and everyday attitudes. Personality and Social Psychology Bulletin, 31, 1099-1111.

Ito, T. (1998). Self-esteem and self-protective and self-enhancing behavior. Japanese Psychological Review, 41, 57-72. (In Japanese with English abstract)

Johnson, M. M. S. (1986). The initial letter effect: Ego-attachment or mere exposure? Unpublished doctoral dissertation, Ohio State University, Department of Psychology.

Jones, J. T., Pelham, B. W., \& Mirenberg, M. C. (2002). Name letter preferences are not merely mere exposure: Implicit egotism as self-regulation. Journal of Experimental Social Psychology, 38, 170-177.

Kitayama, S. \& Karasawa, M. (1997). Implicit self-esteem in Japan: Name letters and birthday numbers. Personality and Social Psychology Bulletin, 23, 736-742.

Koole, S. L., Dijksterhuis, A., \& van, Knippenberg, A. (2001). What's in a name: Implicit selfesteem and the automatic self. Journal of Personality and Social Psychology, 80, 669-685.

Koole, S. L. \& Pelham, B. W. (2003). On the nature of implicit self-esteem: The case of the name letter effect. In S. Spencer, S. Fein, \& M. P. Zanna (Eds.), Motivated Social Perception: The Ontario Symposium, Vol.9 (pp.93-116). Lawrence Erlbaum Associates.

Heatherton, T. F. \& Polivy, J. (1991). Development and validation of a scale for measuring state self-esteem. Journal of Personality and Social Psychology, 60, 895-910.

Nuttin, J. M. (1985) . Narcissism beyond gestalt and awareness: The name letter effect. European Journal of Social Psychology, 15, 353-361.

Nuttin, J. M. (1987). Affective consequences of mere ownership: The name letter effect in twelve European languages. European Journal of Social Psychology, 17, 381-402.

Pelham, B. W., Carvallo, M., \& Jones, J. T. (2005). Implicit egotism. Current Directions in Psychological Science, 14, 106-110.

Pelham, B. W., Mirenberg, M. C., \& Jones, J. T. (2002). Why Susie sells seashells by the seashore: Implicit egotism and major life decisions. Journal of Personality and Social Psychology, 82, 469-487.

Rosenberg, M. (1965) . Society and the Adolescent Self-Image. Princeton, NJ: Princeton University Press.

Taylor, S. E. (1989). Positive illusions: Creative self-deception and the healthy mind. New York: Basic Books.

Wilson, T, D. \& Dunn, E. W. (2004). Self-knowledge: Its limits, value, and potential for 
improvement. Annual Review of Psychology, 55, 493-518. 